\title{
Business Sustainability through Technology Management Approach for Construction Company
}

\author{
Fong Piew, $S^{1}$, Sarip, $S^{2}$, AbdFatah, A. $Y^{3}$ and Kaidi, H. $M^{4}$ \\ ${ }^{1}$ Universiti Teknologi Malaysia, Kuala Lumpur, Malaysia, piew@yahoo.com \\ ${ }^{2}$ Universiti Teknologi Malaysia, Kuala Lumpur, Malaysia, shamsuls.kl@utm.my \\ ${ }^{3}$ Universiti Teknologi Malaysia, Kuala Lumpur, Malaysia, yasser.kl@utm.my \\ ${ }^{4}$ Universiti Teknologi Malaysia, Kuala Lumpur, Malaysia, hazilah.kl@utm.my
}

\begin{abstract}
Throughout the decades, the construction industry was suffered for its business sustainability, mainly due to its poor productivity across the industry. This can be improved through implementing of Technology Management the innovative ways, which consists of BIM, block-chain technology and e-procurement. Throughout the stages of Design, Procure, Execution, and Commissioning, as well as applications on the existing building for the ease of building maintenance. This paper aims to emphasize on the external and internal factors that influence the business transformation towards Technology Management, and its advantages for business sustainability.
\end{abstract}

Key words: Knowledge, Innovation, Procurement, Productivity, Sustainability, Management

\section{INTRODUCTION}

Electrical construction works play vital role in daily life, especially in today's lightning speed living routine that relied so much on electrical appliances in order to access the wonder world of information. Electrical works have to be installed efficiently and safely under the roof for residences, offices, hotels, hospital; as well as those infrastructure works. Construction industry also known for its complexity and large scale; also, poor productivity compared to manufacturing industry. Manufacturing industry has long developed the management system to increase their productivity, as well as continuously monitor their sustainability. Therefore, further research on sustainability and productivity improvement for construction company should be propagated.

Medium size electrical contractors that have approximately 50 employees make the majority in the business segment, and most of them started since the 80s, during the booming of Malaysia's economy. To date, some of their business managements are very much following the standard of procedures (SOP) (IINM, SOP stands for standard operating procedures) as stated in ISO Guidelines; while others do not have a system to be followed and solely depend on the owner to make every single decision. All of these companies are struggling to survive or sustain their business in today's business environment, which eventually will be closing down, due to the inactivity in the industry or killed by project's profitability.

In view of this, it is crucial to identify how the successful factors are able to improve the sustainability for these companies, through knowledge and technical management processes. In this study, the papers were reviewed in sequencing order. This was done by first reviewing and focusing on the involvement of technologies, a transformation in today's business regardless of industry; then further review was done on the knowledge management, and then the innovation management.

\section{BUILDING INFORMATION MODELLING}

Building Information Modelling (BIM) is a transformative technology that offers huge benefits in the entire construction industry, it is an integrated platform that allows the collaboration of multiple information, as well as stakeholders' interaction within one information database [1]. It was first being introduced to Malaysia in the year of 2007, by Construction Industry Development Board (CIDB), Multimedia Super corridor (MSC) and Construction Research Institute Malaysia (CREAM). BIM was not only being applied as technology, but also as a platform or process to improve the involvement of stakeholders in a project, through better communication and information sharing. It was also used to achieve restricted data redundancy, controlled unauthorized information access, transaction processing, integrity enforcement, and data recovery. It brought benefits for all types of construction related activities, be it facility management, existing building refurbishment, or maintenance works for operating building [2]. For a newly build project, it delivered the benefits for early awareness of conflicts in design stage, and scheduled monitoring along the construction period. Besides the immediate benefits that can be experienced at the preliminary stage of a project, it also continuously providing operational benefits like improving the customer experience, operational efficiencies and of business sales. 
As of date, in Malaysia, the adoption of BIM among professionals like architects and engineering firms are still relatively low [3]. Unlike other countries in the European region, especially in the northern region like Denmark, their government had enforced that all projects to be mandatorily adopting BIM by the year 2022; while in Germany, by the year 2020 all public infrastructure projects are required to be mandated. Other countries were using this technology to gain benefits like reducing of utilities bills of a building, along its operation cycle [3]. Currently, most common applications for BIM used in Malaysia are clash detection and coordination, design and visualization, collaboration among stakeholders, and costing estimation. Further usage of BIM is possible to analyze historical data, in order to manage new projects efficiently.

\section{E-PROCUREMNT}

Construction business sustainability is very much depending on their procurement processes as well, as this is one of the important elements to determine the profit for each project, be it completed timely within customer expectation, as well as within allocated budget along the supply chain [4]. The procurement processes can be defined as follows:

i. A process within a firm that authorised specific people or teams with specific responsibilities, to execute the duty of purchasing of various products or services in a construction project.

ii. A unique mechanism to coordinate and link the participants within a construction project throughout the process in a systematic structure, Contractually and better Functionality. Contractually is for risks and responsibilities, while Functionality is for authorities and roles.

The main purpose of the procurement processes is to efficiently deliver a project that fulfilled client's expectations and design criteria [5]. Here some procurement approaches that were practiced in the industry will be further discussed. These discussions were done most commonly by engaging value management, where it is a standardized procedure in delivering a project that complied to the requirements yet not to compromise on reliability and quality. This practice can positively receive support from all of the stakeholders that were encouraging on integration, and better communications throughout the supply chain network. From a previous study, it was pointed out that traditional procurement process within the design and build contract arrangement proven to increase the difficulty for engagement of environmentally friendly material, because of extreme concern from the contractors for the completion dateline and the additional costs incurred [6]. Some researchers identified that using lean techniques is the best procurement practice in construction industry that tremendously increase productivity [7]. Generally, the main elements for lean techniques are waste minimization and processes that include planning and control, continuous development, and strong collaborative connections. Sustainable Procurement (SP) is a process for the team members to address their issues, then to request for services, administration, goods, utilities and works to accomplish the monetary value for long or for long term benefits to the associate members, as well to the macro economy, while controlling the environmental damages [8].

Another common procurement practice that seen incremental usage by the industrial players was through the electronic procurement, or some might have call it ebid [9]. For the application of e-bid at the construction industry, it involved issuing, submitting and collecting tenders, enquiry and order of materials, transactions among contractors, and clients for contract execution. To implement this, additional cost on specialist software and staff trainings were required. And most importantly, the availability of a stable, fast, affordable and reliable internet service. The benefits of e-bid are:

i. Increase the productivity along the construction cycle that enables stakeholders to closely monitor the procurement process, as well as eliminate location barrier among participants.

ii. Reduce the transactional cost within procurement process by improving the procurement data management;

iii. Increase the opportunities and competitiveness among bidders or participants.

A good example of the government's initiatives on implementing e-bid exercise was United Kingdom, the government highly adoption of e-bid into public projects' procurement resulted in a commitment to provide reliable and stable internet services, which in turn also benefit to other users nationwide. For this implementation, previous studies had identified few critical factors that were crucial for developing countries like Malaysia, in sequencing order. The top ten factors identified from this study were presented in Table 1.

From Table 1, it can be seemed that e-bid implementation relied heavily on the involvement of human factors, mainly on the human's commitment and believing on the achievable benefits. With the encouraging attitude towards benefits of e-procurement, it will definitely help to align with current global transformation on procurement practices.

There were a lot of discussions on the benefits for the implementation of e-procurement in a data environment; undoubtedly it has some operational risks that may cause some losses or damages to an organization [10], the failing factors to the operational risks are as follows:

i. Incapability of the organization to implement of corporate systems

ii. The disruption of business activities due to intentional or unintentional actions by employees

iii. Problems from external fraudulent actions

iv. Failure of the ICT system 
Fong Piew, S et al., International Journal of Emerging Trends in Engineering Research, 8(1.1), 2020,22 - 26

Table 1:Top-ten Critical Factors for e-Bid Implementation

\begin{tabular}{|l|l|}
\hline Ranking & Critical Factors \\
\hline 1 & $\begin{array}{l}\text { Availability of reliable and stable } \\
\text { internet services }\end{array}$ \\
\hline 2 & $\begin{array}{l}\text { Availability of skilled personnel to } \\
\text { handle processes and tools }\end{array}$ \\
\hline 3 & Constant power supply \\
\hline 4 & Knowledge for the benefits of e-bid \\
\hline 5 & $\begin{array}{l}\text { Change management plan and training } \\
\text { among stakeholders }\end{array}$ \\
\hline 6 & $\begin{array}{l}\text { Computer literacy among construction } \\
\text { team }\end{array}$ \\
\hline 7 & Confidentiality of e-bid transactions \\
\hline 8 & $\begin{array}{l}\text { Authentication and security of } \\
\text { transactions }\end{array}$ \\
\hline 9 & Top management commitment \\
\hline 10 & Affordability of tools and applications \\
\hline
\end{tabular}

\section{KNOWLEDGE MANAGEMENT}

Construction industry is very knowledge intensive, as it requires high expertise to solve problems. But sadly, most of the construction companies in Malaysia have very limited initiatives to implement knowledge management strategies. Knowledge is an important resource for a company for its competitive advantages [11]. Knowledge management in a company is to transform past experiences and existing information into knowledge database, which to be reused and shared by all employees within the organization and other stakeholders [12]. Previous study suggested that knowledge management consists of six elements [13] as shown in Table 2.

Efficient management of knowledge would allow the company to transfer and apply knowledge among its projects, create synergies within the firm to learn from the mistakes and successes of others, so that it will help to increase the efficiency and productivity.

Table 2:Elements of Knowledge Management

\begin{tabular}{|l|l|}
\hline Elements & Description \\
\hline Knowledge & $\begin{array}{l}\text { Organization culture to define the } \\
\text { value of knowledge is important, as } \\
\text { to encourage team members to } \\
\text { create and share knowledges; } \\
\text { differences of cultural definition to } \\
\text { impact an organization in daily } \\
\text { operation. }\end{array}$ \\
\hline Human Factors & $\begin{array}{l}\text { Employees are the biggest asset of a } \\
\text { company; they play an important } \\
\text { role in transferring knowledge. } \\
\text { Therefore, employees' motivation } \\
\text { and participation are the key factors; } \\
\text { because mistake prevention mindset } \\
\text { makes employees reluctant to } \\
\text { change. }\end{array}$ \\
\hline $\begin{array}{l}\text { Generation of } \\
\text { Information }\end{array}$ & $\begin{array}{l}\text { Online portal like blogs, wikis and } \\
\text { forums allows members in the circle } \\
\text { to create and share knowledge. } \\
\text { Utilization of existing knowledge }\end{array}$ \\
\hline
\end{tabular}

\begin{tabular}{|l|l|}
\hline Knowledge & $\begin{array}{l}\text { helps to improve quality and } \\
\text { efficiency. }\end{array}$ \\
Transfer & $\begin{array}{l}\text { Knowledge transfer in the } \\
\text { construction industry was known to } \\
\text { be difficult, due to the short term } \\
\text { and uniqueness of each project. }\end{array}$ \\
\hline Innovation & $\begin{array}{l}\text { Innovation thinking is named to be } \\
\text { the key success factor for a } \\
\text { company's competitiveness. Staff } \\
\text { must be allowed to develop new } \\
\text { ideas; while management should } \\
\text { strongly encourage innovative and } \\
\text { diversification thinking. }\end{array}$ \\
\hline $\begin{array}{l}\text { Information, } \\
\text { Communication } \\
\text { Technologies }\end{array}$ & $\begin{array}{l}\text { Technologies play vital role to } \\
\text { facilitate the knowledge } \\
\text { management processes in the } \\
\text { multidiscipline environment, it } \\
\text { significantly improves management } \\
\text { processes. The mobile phone } \\
\text { applications on instant messaging } \\
\text { become a digitize platform for } \\
\text { information exchange. }\end{array}$ \\
\hline
\end{tabular}

\section{INNOVATION}

For a very long time, construction industry has been suffering from information transparency and lack of trusts throughout the implementation process [14]. Traditional way of information sharing negatively influencing the trust among project stakeholders, along the supply chain process. Traditionally, technical management cannot guarantee its reliability and transparency. Matters like responsibility on errors, and information modification right encourage the integration between blockchain and BIM.As such, the introduction of blockchain technology will improve the situation by offering a trustworthy infrastructure to manage the information along the stages of design, tender, procurement, construction and commissioning. Blockchain is a methodology which enables to manage contracts and transactions that are secured and organized [15]. Data or information distributed through BIM and blockchain integration can be considered as the only reliable data. Two major benefits can be expected through the integration:

i. Creation of a single yet reliable register that defines the duties and responsibilities of each other, transparently. Thus, eliminate or reduce conflicts or misunderstanding among the stakeholders.

ii. Possibility to automate the delivery phases.

Blockchain comes from Distributed Ledger Technology (DLT) that is distributing data logging and maintenance system, which solely depends on the consensus mechanism by the agents. The autonomy and the update of the contained information in blocks are subjected to authorization and verification by all participants. This technology avoids the structural alteration and violation of contents, due to the same information to be entered and validated within the chain are distributed, then stores in 
the nodes. Thanks to the consensus mechanism that verify, validate and control processes in the entire network, this resulting the information being very true and unchangeable [15]. The implementation of BIM and blockchain integration can be categorized into four phases, as per Table 3 .

Table 3:Blockchain integration in phases

\begin{tabular}{|l|l|}
\hline Phases & Description \\
\hline Design & $\begin{array}{l}\text { Exchange and sharing of project } \\
\text { information via a collaborative } \\
\text { environment }\end{array}$ \\
\hline Tender & $\begin{array}{l}\text { Transparency procedure and selection } \\
\text { criteria for tender evaluation that are } \\
\text { accessible by all participants, } \\
\text { minimizing misunderstanding among } \\
\text { administration executers }\end{array}$ \\
\hline Construction & $\begin{array}{l}\text { Make it traceable along the supply } \\
\text { chain, as well as monitoring the } \\
\text { construction progress. Automatic } \\
\text { payment system also possible to be } \\
\text { implemented, according to the stages of } \\
\text { predetermined contract milestone. }\end{array}$ \\
\hline Life-Cycle & $\begin{array}{l}\text { Utilize of data collected during } \\
\text { construction period, for future } \\
\text { maintenance, renovation, or even } \\
\text { dismantling processes during the } \\
\text { operational period. }\end{array}$ \\
\hline
\end{tabular}

The main benefits for a construction company to be innovative, are to be energy and resource efficient [16]. Besides using the innovative ways to manage and construct a project, innovative building material and applications may also be used to achieve better efficiency;

i. Recycling roof shingles from production waste;

ii. Using recycled aggregate concretes.

iii. Using fiber-carbon reinforced concrete to reduce surrounding carbon dioxide.

iv. Using Building Integrated Photovoltaic to be part of the roof structure, yet convert solar energy into electricity; as well as hot water.

v. Recycling rainwater for toilet flushing system.

vi. Using reversible cooling system for room temperature control.

Furthermore, the integration of Building Management System (BMS) must not be forgotten, engaging BMS to create an intelligent building can significantly reduce consumption and minimizing waste of water, energy and fuel.

Innovation is one of the key elements for competitive advantage and be recognized as imperative action for one's survival and achievement. However, undoubtedly innovation has to be introduced systematically, and very much depends on how a company manage and allocate its available resources. Innovation is when ideas meet the expectations and requirements of the industry, it is economically viable and offers financial return to the organization, so it should not just be focused on knowledge, but economic performance as well [17]. Many innovative proposals that were found in the commercial and practical applications were not necessarily using cutting edge technologies [18].

\section{DISCUSSION}

Knowledge management allows the company to transfer the knowledge learned from the existing projects, for the success of future projects, as well as to increase the performance and productivity. As such, both organization culture and personnel mentality needed to be aligned for the success of knowledge management, and further promote innovation within an organization. Encouragement of new ideas cannot be forgotten as well, because creativity is the key element for innovation.

\section{CONCLUSION}

This paper presents Business Sustainability through Technology Management Approach for Construction Company, and we have identified some critical factors that affecting construction companies' sustainability, through literature review.

Individual's initiatives and intention are the crucial attributes among Malaysian contractors. Besides dealing with new projects development, engagement of BIM technology is possible for the existing building as well. Using Three-Dimensional scanning technology can help to produce the most accurate BIM building model, in the shortest period on basis of dimensional measurements. With this digitized information on the existing building, it will not only bringing benefits for the building maintenance that costs a big portion of the entire building lifecycle operational cost, but it also very useful and helpful during emergency situation like firefighting, where the fire brigade is able to access accurate information, to save the life in danger instead of the traditional ways of taking measurements with laser rangefinder, and measurements extract from drawings, which most of the cases are inaccurate.

\section{ACKNOWLEDGEMENT}

This work is supported by Universiti Teknologi Malaysia under University GrantQ.K130000.3556.07G32 and Q.K130000.3556.06G45 for the financial support provided throughout the course of this research project.

\section{REFERENCES}

1. R. J. D. Zhabrinna, M. M. A. Pratama and M. Yusuf.BIM adoption towards the sustainability of construction industry in Indonesia, in Web of Conference, 2018, No. 195.

2. S. Z. N. Siniak,V. Nikolaiev and S. Shavrov. Building Information Modelling for Housing Renovation - Example for Ukraine,Real Estate Management and Valuation,vol.27, no.2,July 2019. 
3. N. Zhang.Analysis of Influencing Factors of Construction Engineering Management and Discussion of Strategies, in ICTETS, Materials Science and Engineering, 2019, vol.688, no. 5, pp. 055067.

4. M. S. P. Pöyhönena and J. K. Kajandera. Developing a project delivery system for construction project - a case study, in Creative Construction Conference,2017,Vol.196, pp. 520526.

5. S. G. Akdag and U.M aqsood.A roadmap for BIM adoption and implementation in developing countries: the Pakistan case,International Journal of Architectural Research, vol. 14, pp. 112-132, Sept 2019.

6. L. O. Siguencia and P. Halemba. Automation of management processes, in E3S Web of Conferences, 2019,vol.132, pp. 01020. https://doi.org/10.1051/e3sconf/201913201020

7. N. Shovunova,D. Vorobyev, V. Dikareva, S. Archakova and Y. Serebryakova.Development of an assessment methodology for innovation activity of construction enterprises, in International Science Conference,2018,vol.170, pp. 01095.

8. Z. C. L. Zhang and Q. He, P. Zhai.Investigating the Constraints to Buidling Information Modeling (BIM) Applications for Sustainable Building Projects: A Case of China,Sustainability, MDPI, Open Access Journal,vol.11, pp. 63-80, March 2019.

9. S. T. S. Tiwari, S. W.Chan and M. F. Mubarak. Critical analysis of procurement techniques in construction management sectors, in IOP Conf. Ser.: Materials Science and Engineering2018, vol.342, pp. 012100.

10. T. Kostyunina.Classification of operational risks in construction companies on the basis of big data,in International Scientific Conference Environmental Science for Construction Industry, 2018, vol.193.

11. A. A. R. Barbosa and M.V.Innovation and construction management in Brazil: Challenges of companies in times of quality and productivity, in IOP Conf. Ser.: Materials Science and Engineering,2017,vol. 251.

12. K. Prušková.Possibilities of Using Modern Technologies and Creation of the Current Project Documentation Leading to the Optimal Management of the Building for Sustainable Development, in IOP Conference Series: Earth and Environmental Science, 2019, vol. 290.

13. A. L. Castro, V. Yepes, E. Pellicer andA. J. Cuellar.Knowledge management in the construction industry: state of the art and trends in research,Revista de la Construcción, 2012,vol.11, no. 3, pp. 62-73.

14. F. Anastasia.Application of knowledge management on project management in construction,in Innovative Technologies in
Environmental Science and Education, 2019, Vol.135.

15. G. M. Di Giuda,G. Pattini, E. Seghezzi, M. Schievano and F. Paleari.The Construction Contract Execution Through the Integration of Blockchain Technology. Digital Transformation of the Design, Construction and Management Processes of the Built Environment, 2020,pp. 27-36.

16. O. Sinoh and Z. Ibrahim.Factors affecting success and difficulty to adopt Building Information Modelling (BIM) among construction firms in Sabah and Sarawak, in IOP conf: Materials Science and Engineering, 2018, vol. 431.

17. W. Arkadiusz and P.Gilewski. Innovative Technologies in Construction Sector that Meet Criteria of Sustainable Development, in IOP conf: Materials Science and Engineering,2019, vol. 661.

18. N. Shovunova, D. Vorobyev, V. Dikareva, S. Archakova andY. Serebryakova.Development of an assessment methodology for innovation activity of construction enterprises, MATEC Web of Conferences, 2018,vol. 170. 